\title{
PENGARUH PENERAPAN MODEL PEMBELAJARAN POE2WE BERBASIS HANDS ON ACTIVITY PADA MATERI INDUKSI ELEKTROMAGNETIK TERHADAP KEMAMPUAN BERPIKIR KRITIS SISWA
}

\author{
Ilham Mubarok ${ }^{1}, \mathrm{Nana}^{2}$, Dwi Sulistyaningsih ${ }^{3}$ \\ ${ }^{1}$ Mahasiswa Program Studi Pendidikan Fisika, Universitas Siliwangi \\ ${ }^{2}$ Dosen Program Studi Pendidikan Fisika, Universitas Siliwangi \\ ${ }^{3}$ Dosen Program Studi Pendidikan Fisika, Universitas Siliwangi \\ Universitas Siliwangi Tasikmalaya \\ *Email: ilhammubarok05@gmail.com
}

\begin{abstract}
Abstrak: Model pembelejaran POE2WE merupakan model pembelajaran yang dikembangkan untuk mengetahui pemahaman siswa mengenai suatu konsep dengan pendekatan konstruktivistik. Dengan kata lain, pembelajaran yang menggunakan konstruktiv siswa sebagai pusat pada pembelajaran. Hands On activity adalah suatu kegiatan yang dirancang untuk melibatkan siswa dalam mencari informasi dan bertanya, beraktivitas dan menemukan, mengumpulkan data dan menganalisis, serta membuat kesimpulan sendiri. Latar belakang masalah penelitian ini karena masih banyak siswa yang belum mempunyai pikiran yang kritis, hanya mendapatkan satu pengalaman pembelajaran yaitu guru. Dengan bantuan model hands-on activity, penulis mengharapkan siswa akan lebih aktif dan berpikir kritis. Penelitian ini menggunakan metode literasi (studi pustaka) dengan referensi yang relevan. Berdasarkan hasil penilitian yang dilakukan oleh (Andi dkk, 2015), mengungkapkan bahwa skor kemampuan berpikir kritis kelas eksperimen lebih tinggi dari skor hasil belajar kelompok kontrol. Oleh karena itu, dapat disimpulkan bahwa model pembelajaran Hands On Activity efektif terhadap berpikir kritis serta aktif dalam interaksi sosial. Selain itu pada pembelajaran POE2WE akan memudahkan guru dengan melibatkan siswa akan lebih aktif, dan merefleksikan pemahaman baru sesuai pengetahuan awal yang dimiliki pada siswa.
\end{abstract}

Kata Kunci: POE2WE, Hands on activity, berpikir kritis, aktif.

Abstract: The POE2WE learning model is a learning model developed to determine students' understanding of a concept with a constructivist approach. In other words, learning that uses student constructs as the center of learning. Hands On activity is an activity designed to involve students in seeking information and asking questions, doing activities and finding, collecting data and analyzing, and making their own conclusions. The background of this research problem is because there are still many students who do not have critical thoughts, only get one learning experience, namely the teacher. With the help of the hands-on activity model, the authors expect students to be more active and think critically. This research uses literacy method (literature study) with relevant references. Based on the results of research conducted by (Andi et al., 2015), it was revealed that the critical thinking ability score in the experimental class was higher than the learning outcome score of the control group. Therefore, it can be concluded that the Hands On Activity learning model is effective for critical thinking and is active in social interactions. In addition, POE2WE learning will make it easier for teachers by involving students to be more active, and reflect on new understandings according to the initial knowledge that students have.

Keywords: POE2WE, Hands on activity, critical thinking, active. 


\section{PENDAhuluan}

Peraturan Pemerintah Republik Indonesia Nomor 19 Tahun 2005 dalam UndangUndang Republik Indonesia Nomor 20 (2003) tentang Standar Nasional Pendidikan pasal 1 menjelaskan bahwa tujuan Standar Nasional Pendidikan adalah menjamin mutu pendidikan nasional dalam rangka mencerdaskan kehidupan bangsa dan membentuk watak serta peradaban bangsa yang bermartabat. Dalam mewujudkan Standar Nasional Pendidikan tersebut, pemerintah selalu berusaha dalam memperbaiki dan mengembangkan sistem pendidikan di Indonesia ke arah yang lebih baik dan bagus. Salah satunya usaha pemerintah pada sistem pendidikan yaitu dengan adanya kurikulum baru. Kurikulum baru diharapkan dapat memperbaiki dan mengembangkan sistem pendidikan.

Melalui proses pembelajaran, guru dituntut untuk mampu membimbing dan memfasilitasi siswa agar mereka dapat memahami kekuatan serta kemampuan yang mereka miliki, dengan memberi motivasi agar siswa terdorong untuk bekerja ataupun belajar sebaik mungkin untuk mewujudkan keberhasilan berdasarkan kemampuan yang mereka miliki. Sehingga mengakibatkan hasil belajar yang kurang maksimal dan kurang memuaskan, itu dapat dilihat dari banyaknya siswa yang mendapatkan nilai rendah dan tidak mencapai KKM. Salah satu alternatif nya yaitu menggunakan model pembelajaran yang dapat membantu siswa untuk belajar aktif dan bertanggung jawab serta berfikir kritis untuk memahami mata pelajaran, baik pembelajaran secara bekerja sama, secara berkelompok maupun individual, sehingga proses pembelajaran lebih menyenangkan dan tidak membosankan.

Kerjasama yang dilakukan mereka lakukan justru pada waktu yang kurang tepat yaitu pada saat ada tugas individu, ulangan atau kegiatan sejenisnya yang seharusnya tidak melakukan kerjasama. Kurangnya kerja sama dan saling memperhatikan di antara siswa pada saat pembelajaran berlangsung mengakibatkan munculnya perbedaan pemahaman konsep tentang materi yang dipelajari. Akibatnya siswa yang berinteraksi dan bekerja sama dalam pembelajaran dapat memperoleh hasil belajar yang lebih baik ketika diadakan evaluasi dibandingkan siswa yang tidak melakukan hal tersebut.

Dan penggunaan model pembelajaran yang tepat ini merupakan sebagai strategi untuk membantu membimbing siswa mencapai kompetensi yang diharapkan dan mampu meningkatkan pemahaman siswa serta mencapai hasil belajar yang maksimal.

Salah satu tujuan pembelajaran fisika adalah mengembangkan kemampuan bernalar dalam berpikir analisis induktif dan deduktif dengan menggunakan konsep dan prinsip fisika untuk menjelaskan berbagai peristiwa alam dan menyelesaikan masalah baik secara kualitatif maupun secara kuantitatif. Salah satu bagian dari kemampuan berpikir tersebut adalah kemampuan berpikir kritis. Berpikir kritis adalah salah satu dari sekian banyak kemampuan penting dalam berpikir yang harus dimiliki oleh siswa karena berpikir kritis membuat seseorang mudah untuk berproses dan menggunakan informasi untuk menemukan solusi dari suatu permasalahan. (riyan setiawan dkk, 2017:7)

Berpikir kritis adalah proses disiplin yang secara intelektual aktif dan terampil mengkonseptualisasi, menerapkan, menganalisis, mensintesis, dan atau mengevaluasi 
informasi yang dikumpulkan dari atau dihasilkan oleh, pengamatan, pengalaman, refleksi, penalaran, atau komunikasi, sebagai panduan untuk kepercayaan dan tindakan (Tawil, 2013:7).

Kemampuan berpikir kritis siswa sangat perlu dikembangkan demi keberhasilan mereka dalam pendidikan dan dalam kehidupan bermasyarakat. Komponen penting dari disposisi berpikir kritis akan memiliki karakteristik tertentu dan keterampilan tertentu. Berdasarkan dimensi kognitif Bloom yang telah direvisi, maka kemampuan berpikir kritis menempati bagian dimensi analisis (C4), dan evaluasi (C5).

Hands on activity adalah suatu model yang dirancang untuk melibatkan siswa dalam menggali informasi dan bertanya, beraktivitas dan menemukan, mengumpulkan data dan menganalisis serta membuat kesimpulan sendiri. Siswa diberi kebebasan dalam mengkonstruk pemikiran dan temuan selama melakukan aktivitas sehingga siswa melakukan sendiri dengan tanpa beban, menyenangkan dan dengan motivasi yang tinggi. Kegiatan ini menunjang sekali pembelajaran kontekstual dengan karakteristik sebagaimana disebutkan oleh (Hatta dalam Moh. Amin, 2007:2) yaitu: kerjasama, saling menunjang, gembira, belajar dengan bergairah, pembelajaran terintegrasi, menggunakan berbagai sumber, siswa aktif, menyenangkan, tidak membosankan, sharing dengan teman, siswa kritis dan guru kreatif.

Melalui Hands on Activity diharapkan siswa dapat memperoleh manfaat antara Iain meningkatkan motivasi, minat, mengatasi masalah belajar, menghubungkan kejadian yang konkrit dan yang abstrak, menghindarkan salah paham dan mendapatkan umpan balik dari siswa.

Selain dengan model Hands on Activity, dapat juga digunakan model pembelajaran POE2WE. Model POE2WE merupakan model pembelajaran yang dikembangkan untuk mengetahui pemahaman peserta didik mengenai suatu konsep dengan pendekatan konstruktivistik. Model ini membangun pengetahuan dengan urutan proses yaitu meramalkan atau memprediksi solusi dari permasalahan, melakukan eksperimen untuk membuktikan prediksi, kemudian menjelaskan hasil eksperimen yang diperoleh secara lisan maupun tertulis, membuat contoh penerapan dalam kehidupan sehari-hari, menuliskan hasil diskusi dan memuat evaluasi tentang pemahaman peserta didik baik secara lisan maupun tertulis (Nana et al., 2014).

\section{METODE PENELITIAN}

Metode yang digunakan dalam artikel ini adalah studi literature atau studi pustaka. Data dikumpulkan dan dianalisis disajikan dalam hasil dan pembahasan untuk menarik kesimpulan. Adapun sumber data yaitu literatur dapat berupa buku, artikel ilmiah, jurnal penelitian, laporan hasil penelitian, prosiding seminar dan lain sebagainya yang berkaitan dengan variabel yang menjadi objek penelitian. Variabel yang dimaksud adalah hal-hal yang berkaitan dengan pengaruh model pembelajaran POE2WE berbasis Hands On Activity terhadap berfikir kritis siswa. 


\section{HASIL PENILITIAN DAN PEMBAHASAN}

\subsection{Model $\mathrm{POE}_{2} \mathrm{WE}$}

Penggabungan tahapan-tahapan pembelajaran model POEW dan model pembelajaran Fisika dengan Pendekatan Konstruktivistik maka dapat di susun langkah-langkah pembelajaran model POE2WE secara terinci sebagai berikut: (Nana dan Endang Surahman, 2019:84-85)

a. Prediction

Tahap prediction yaitu peserta didik membuat prediksi atau dugaan awal terhadap suatu permasalahan. Permasalahan yang ditemukan berasal dari pertanyaan dan gambar tentang materi yang disampaikan oleh guru yang ada di Lembar Kerja peserta didik (LKS)/buku peserta didik sebelum peserta didik membuat prediksi. Pembuatan prediksi jawaban tahap Prediction pada model POEW identik dengan fase Engagenent pada pendekatan konstruktivistik. Guru mengajukan pertanyaan yang dapat mendorong peserta didik untuk dapat membuat prediksi atau jawaban sementara dari suatu permasalahan.

b. Observation

Tahap Observation yaitu untuk membuktikan prediksi yang telah di buat oleh pesera didik. Peserta didik diajak melakukan eksperimen berkaitan dengan masalah atau persoalan yang di temukan. Selanjutnya peserta didik mengamati apa yang terjadi, kemudian peserta didik menguji kebenaran dari dugaan sementara yang telah dibuat. Tahap Observation pada model POEW identik dengan fase Exploration pada pendekatan konstruktivistik.

c. Explanation

Tahap Explanation atau menjelaskan yaitu peserta didik memberikan penjelasan terhadap hasil eksperimen yang telah dilakukan. Penjelasan dari peserta didik dilakukan melalui diskusi dengan anggota kelompok kemudian tiap kelompok mempresentasikan hasil diskusinya di depan kelas. Jika prediksi yang di buat peserta didik ternyata terjadi di dalam eksperimen, maka guru membimbing peserta didik merangkum dan memberi penjelasan untuk menguatkan hasil eksperimen yang dilakukan. Namun jika prediksi peserta didik tidak terjadi dalam eksperimen, maka guru membantu peserta didik mencari penjelasan mengapa prediksi atau dugaannya tidak benar. Tahap explanation identik dengan fase explanation pada pendekatan konstuktivistik.

d. Elaboration

Tahap elaboration yaitu peserta didik membuat contoh atau menerapkan konsep dalam kehidupan sehari-hari. Tahap elaboration di ambil dari pendekatan konstruktivistik. Tahap ini guru medorong peserta didik untuk menerapkan konsep baru dalam situasi baru sehingga peserta didik lebih memahami konsep yang di ajarkan guru. Tahap ini pengembangan dari pendekatan konstruktivistik. 
e. Write

Tahap write atau menulis yaitu melakukan komunikasi secara tertulis,merefleksikan pengetahuan dan gagasan yang dimiliki peserta didik Menurut Masingilia dan Wisniowska (1996) dalam (Yamin \& Ansari, 2012) menulis dapat membantu peserta didik untuk mengekspresikan pengetahuan dan gagasan mereka. peserta didik menuliskan hasil diskusi dan menjawab pertanyaan yang ada pada LKS. Selain itu pada tahap write ini, peserta didik membuat kesimpulan dan laporan dari hasil eksperimen. Tahap ini merupakan pengembangan dari model TTW.

f. Evaluation

Tahap Evaluation yaitu evaluasi terhadap pengetahuan, keterampilan dan perubahan proses berfikir peserta didik. Pada tahap ini peserta didik di evaluasi tentang materi gerak lurus berupa lisan maupun tulisan. Tahap ini merupakan pengembangan dari pendekatan konstruktivistik.

Tabel 1. Sintaks Pengembangan model POE2WE

\begin{tabular}{|c|c|c|c|}
\hline No. & $\begin{array}{l}\text { Sintaks POEW } \\
\text { (Samosir, 2010) }\end{array}$ & $\begin{array}{c}\text { Sintaks model } \\
\text { Pembelajaran dengan } \\
\text { Pendekatan } \\
\text { Konstruktivistik } \\
\text { (Duffy \& Jonassen, } \\
\text { 1992) }\end{array}$ & $\begin{array}{c}\text { Model POE2WE (Nana et } \\
\text { al., 2014) }\end{array}$ \\
\hline 1. & $\begin{array}{l}\text { (Prediction) } \\
\text { membuat } \\
\text { prediksi, } \\
\text { membuat } \\
\text { dugaan }\end{array}$ & $\begin{array}{l}\text { (Engagement) } \\
\text { pendahuluan membuat } \\
\text { pertanyaan menggali } \\
\text { pengetahuan } \\
\text { awalpeserta didik. }\end{array}$ & $\begin{array}{l}\text { (Prediction) Membuat dugaan } \\
\text { atau prediksi. Tahap } \\
\text { Engagement identik dengan } \\
\text { Predict pada POEW }\end{array}$ \\
\hline 2. & $\begin{array}{l}\text { (Observation) } \\
\text { Melakukan } \\
\text { penelitian, } \\
\text { pengamatan }\end{array}$ & $\begin{array}{l}\text { (Exploration) menguji } \\
\text { prediksi ,melakukan dan } \\
\text { mencatat rasil } \\
\text { pengamatan. }\end{array}$ & $\begin{array}{l}\text { (Observation) Melakukan } \\
\text { observasi/pengamatan Tahap } \\
\text { Exploration identik dengan } \\
\text { tahap observation pada } \\
\text { POEW. }\end{array}$ \\
\hline 3. & $\begin{array}{l}\text { (Explanation) } \\
\text { Yaitu memberi } \\
\text { penjelasan }\end{array}$ & $\begin{array}{l}\text { (Explation) } \\
\text { menjelaskan konsep } \\
\text { dengan kalimat mereka } \\
\text { sendiri }\end{array}$ & $\begin{array}{l}\text { (Explation) Menjelaskan Pada } \\
\text { tahap explanation identik } \\
\text { dengan explation pada } \\
\text { pendekatan konstruktivistik }\end{array}$ \\
\hline 4. & $\begin{array}{l}\text { (Write) } \\
\text { Membuat } \\
\text { kesimpulan }\end{array}$ & $\begin{array}{l}\text { (Elaboration) Aplikasi } \\
\text { konsep dalam } \\
\text { kehidupan sehari-hari }\end{array}$ & $\begin{array}{lr}\text { (Elaboration) } & \text { Aplikasi } \\
\text { konsep dalam } & \text { kehidupan } \\
\text { sehari-hari } & \text { merupakan } \\
\text { pengembangan } & \text { dari } \\
\text { pendekatan Konstruktivistik }\end{array}$ \\
\hline 5. & & $\begin{array}{l}\text { (Evaluation) Evaluasi } \\
\text { terhadap pengetahuan, } \\
\text { keterampilan }\end{array}$ & $\begin{array}{l}\text { (Write) Menuliskan hasil } \\
\text { diskusi sebagai kesimpulan. }\end{array}$ \\
\hline
\end{tabular}




\begin{tabular}{|c|c|c|}
\hline & $\begin{array}{l}\text { perubahan proses } \\
\text { berfikir peserta didik }\end{array}$ & $\begin{array}{l}\text { Merupakan pengembangan } \\
\text { dari model POEW }\end{array}$ \\
\hline 6. & & $\begin{array}{lr}\text { (Evaluation) } & \text { Evaluasi } \\
\text { terhadap efektifitas fase-fase } \\
\text { sebelumnyar Merupakan } \\
\text { pengembangan } \\
\text { pendekatan Konstruktivistik }\end{array}$ \\
\hline
\end{tabular}

Sumber: Nana, N., \& Surahman, E. Pengembangan Inovasi Pembelajaran Digital Menggunakan Model Blended POE2WE di Era Revolusi Industri 4.0. In Prosiding SNFA (Seminar Nasional Fisika dan Aplikasinya) (Vol. 4, pp. 8290).

Tabel 2. Kegiatan pembelajaran Model Pembelajaran Model $\mathrm{POE}_{2} \mathrm{WE}$

\begin{tabular}{|c|c|c|}
\hline Fase- fase & Kegiatan Guru & Kegiatan Peserta Didik \\
\hline Prediction & $\begin{array}{ll}\text { - } & \text { Menyampaikan tujuan } \\
\text { pembelajaran. } \\
\text { - } \\
\text { Mengajukan pertanyaan } \\
\text { kepada siswa } \\
\text { - Menginventarisir prediksi } \\
\text { dan alasan yang di } \\
\text { kemukakan peserta didik. }\end{array}$ & $\begin{array}{ll}\text { - } & \text { Memperhatikan } \\
\text { penjelasan dari guru. } \\
\text { - } & \text { Memprediksi jawaban } \\
\text { pertanyaan dari guru } \\
\text { - } \\
\text { Mendiskusikan hasil } \\
\text { prediksinya }\end{array}$ \\
\hline Observation & $\begin{array}{ll}\text { - } & \text { Mendorong peserta didik } \\
\text { untuk bekerja secara } \\
\text { kelompok } \\
\text { - } \\
\text { - } \\
\text { Membagikan LKS } \\
\text { pengawasi kegiatan } \\
\text { oleh peserta didik }\end{array}$ & $\begin{array}{ll}\text { - } & \text { Membentuk kelompok } \\
\text { - } & \text { Melakukan percobaan } \\
\text { - } & \text { Mengumpulkan data } \\
& \text { hasil percobaan } \\
\text { - } & \text { Melakukan diskusi } \\
& \text { kelompok } \\
\text { - } & \begin{array}{l}\text { Menyimpulkan hasil } \\
\text { percobaan }\end{array}\end{array}$ \\
\hline Explanation & $\begin{array}{l}\text { - Mendorong peserta didik } \\
\text { untuk menjelaskan hasil } \\
\text { percobaan. } \\
\text { Meminta peserta didik } \\
\text { pempresentasikan hasil } \\
\text { percobaannya } \\
\text { - } \begin{array}{l}\text { Mengklarifikasikan hasil } \\
\text { percobaannya }\end{array} \\
\text { - } \begin{array}{l}\text { Menjelaskan } \\
\text { konsep/definisi baru }\end{array}\end{array}$ & 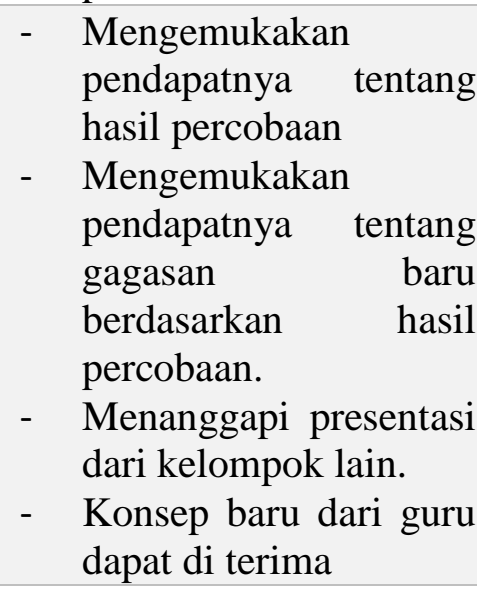 \\
\hline Elaboration & $\begin{array}{l}\text { Memberi permasalahan } \\
\text { berkaitan dengan } \\
\text { penerapan konsep. }\end{array}$ & $\begin{array}{l}\text { - Menerapkan konsep } \\
\text { baru dalam situasi baru } \\
\text { atau kehidupan sehari- } \\
\text { hari. }\end{array}$ \\
\hline
\end{tabular}




\begin{tabular}{|c|c|c|}
\hline & 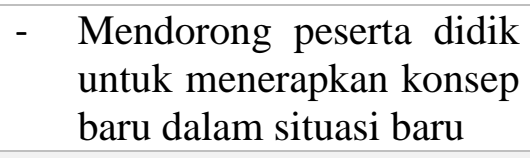 & \\
\hline Write & $\begin{array}{l}\text { - Memberi kesempatan } \\
\text { kepada peserta didik untuk } \\
\text { mencatat hasil diskusi } \\
\text { serta kesimpulan. }\end{array}$ & $\begin{array}{lr}\text { - } & \text { Mencatat } \\
\text { penjelasan } & \text { dan } \\
\text { kesimpulan dari guru } & \text { gun diskusi kelompok }\end{array}$ \\
\hline Evaluation & 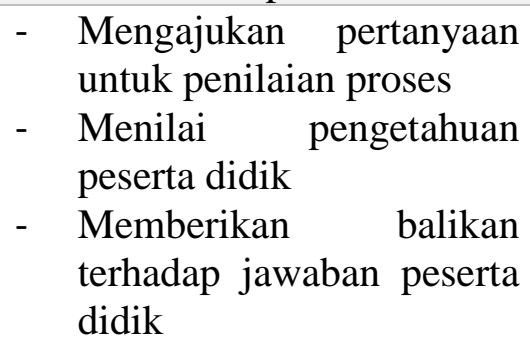 & $\begin{array}{l}\text { - Menjawab pertanyaan } \\
\text { berdasarkan data } \\
\text { - Mendemonstrasikan } \\
\text { kemampuan dalam } \\
\text { penguasaan konsep }\end{array}$ \\
\hline
\end{tabular}

Sumber: Nana, N., \& Surahman, E. Pengembangan Inovasi Pembelajaran Digital Menggunakan Model Blended POE2WE di Era Revolusi Industri 4.0. In Prosiding SNFA (Seminar Nasional Fisika dan Aplikasinya) (Vol. 4, pp. 8290).

\subsection{Hands On Activity}

Hand On Activity adalah suatu model yang dirancang untuk melibatkan siswa dalam menggali informasi dan bertanya, beraktivitas dan menemukan, mengumpulkan data dan menganalisis serta membuat kesimpulan sendiri. Siswa diberi kebebasan dalam mengkonstruksi pemikiran dan temuan selama melakukan aktivitas sehingga siswa melakukan sendiri dengan tanpa beban, menyenangkan dan dengan motivasi yang tinggi. (Saonah, 2013).

Melalui hands on activity akan terbentuk suatu penghayatan dan pengalaman untuk menetapkan suatu pengertian (penghayatan) karena mampu membelajarkan secara bersama-sama kemampuan psikomotorik (keterampilan), pengertian (pengetahuan) dan afektif (sikap) yang biasanya menggunakan sarana laboratorium dan atau sejenisnya. Juga, dapat memberikan penghayatan secara mendalam terhadap apa yang dipelajari, sehingga apa yang diperoleh oleh siswa tidak mudah dilupakan. Pada hands on activity siswa akan memperoleh pengetahuan tersebut secara langsung melalui pengalaman sendiri.

Model pembelajaran hands on activity merupakan model pembelajaran yang direncanakan untuk membantu peserta didik mengembangkan kemampuan berpikir tingkat tinggi, dalam hal ini bahwa selama proses pembelajaran peserta didik dilibatkan dalam pembelajaran secara aktif dan mendorong kemampuan peserta didik untuk memahami materi yang disampaikan atau mereka yang akan memikirkan sendiri terhadap apa yang telah mereka alami dalam kehidupan sehari-harinya, sehingga kemampuan berpikir kritis peserta didik bisa meningkat. 


\subsection{Pengaruh penerapan Model Pembelajaran POE2WE berbasis Hand On Activity terhadap berfikir kritis pada materi induksi elektromagnetik}

Hasil penelitian (Andi dkk, 2015) Mengungkapkan bahwa pembelajaran fisika menggunakan Hands on activity lebih baik dari pada siswa yang diajar menggunakan pembelajaran konvensional, siswa sangat antusias mengikuti pembelajaran, mulai terlihat aktif dalam proses pembelajaran serta siswa mampu menjelaskan kembali apa yang mereka telah pahami. Perubahan aktifitas siswa pun dapat terlihat misalnya ketika penjelasan oleh guru yang kurang mengerti maka siswa akan berani bertanya. Dari perubahan aktifitas siswa ini setelah diterapkan pembelajaran berbasis hands on activity dapat disimpulkan bahwa hasil belajar pun mengalami peningkatan meskipun perbedaannya tidak signifikan.

Tabel 3. Hasil penelitian skor kemampuan berfikir kritis fisika kelompok kontrol dan kelompok eksperimen pada siswa SMA (Andi dkk, 2015)

\begin{tabular}{|c|c|c|}
\hline \multirow{2}{*}{ Statistik } & \multicolumn{2}{|c|}{ Nilai Statistik } \\
\hline & Kelompok Eksperimen & Kelompok Kontrol \\
\hline Ukuran sampel & 38 & 38 \\
\hline Skor tertinggi & 30 & 27 \\
\hline Skor terendah & 17 & 12 \\
\hline Rentang skor & 13 & 15 \\
\hline Skor rata & 24,66 & 20,08 \\
\hline Standar deviasi & 2,93 & 3,98 \\
\hline Varians & 8,58 & 15,84 \\
\hline
\end{tabular}

Dari hasil yang diperoleh, memang tidak memiliki perbedaan yang signifikan akan tetapi pembelajaran ini sudah berhasil diterapkan.

Fisika merupakan bagian dari sains adalah pengetahuan yang telah disusun secara sistematis, terorganisir, didapatkan melalui observasi dan eksperimentasi (Nurjanah dkk, 2013). Berdasarkan pengertian ini, pembelajaran fisika harus diawali dengan observasi dan eksperimen. Alat eksperimen induksi elektromagnetik alternatif adalah KIT alternatif yang dapat digunakan guru dan siswa SMA dalam pembelajaran fisika khususnya pada topik induksi elektromagnetik. Alat eksperimen induksi elektromagnetik alternatif dibuat sepraktis mungkin agar dalam pembelajaran fisika pada materi induksi elektromagnetik guru mudah menyajikan materi pembelajaran dengan metode eksperimen sehingga siswa dapat belajar induksi elektromagnetik dengan pengamatan-pengamatan gejala fisika secara nyata, hal ini mengingat karena materi induksi elekromagnetik sulit diamati secara kasat mata.

Beberapa eksperimen yang dapat dilakukan dengan perangkat eksperimen induksi elektromagnetik alternatif adalah gejala induksi jamping ring, hukum Faraday, konsep transformator, dan siswa dapat mengamati gejala yang muncul dengan berbagai bahan inti induksi. beberapa hal yang perlu diketahui pada perangkat eksperimen induksi 
elektromagnetik yang dikembangkan yaitu alat eksperimen induksi elektromagentik alternatif dibuat sederhana agar guru fisika SMA mudah menyajikan pembelajaran dengan metode percobaan atau eksperimen, dengan adanya bimbingan guru siswa dapat melakukan proses ilmiah dan menemukan konsep fisika dalam pembelajaran induksi elektromagnetik dengan beberapa pengamatan gejala fisika secara langsung sehingga dalam pembelajaran induksi elektromagnetik siswa mendapat pengalaman nyata (kontekstual).

Menurut siswa buku modul percobaan atau eksperimen juga memberikan kemudahan dalam pelaksanaan praktikum, hampir semua aspek penlilaian pada buku modul memperoleh nilai pada kriteria yang sangat tinggi. Siswa menliai bahwa tujuan eksperimen mudah dipahami, alat dan bahan mudah dipahami, penggunaan gambar dapat mempermudah siswa melakukan langkah eksperimen, langkah-langkah eksperimen mudah dipahami dan diikuti, selain itu siswa berpendapat bahwa waktu eksperimen menjadi lebih singkat dengan buku panduan penggunaan alat eksperimen (Hendro Angga dkk, 2016). Seperti yang diungkapkan oleh Nana Sudjana (2007) bahwa makna praktis media pembelajaran diantaranya adalah bahan pengajaran hendaknya mempunyai makna yang jelas sehingga dapat lebih mudah dipahami oleh siswa, dan memungkinkan siswa menguasai tujuan pengajaran yang lebih baik.

Selain itu pembelajaran dengan POE2WE akan memudahkan guru melibatkan siswa lebih aktif, dan merefleksikan pemahaman baru sesuai pengetahuan awal yang dimiliki. Pembelajaran POE2WE dapat disesuaikan dengan tujuan pembelajaran dan kebutuhan siswa. Metode POE2WE bagi siswa akan memperoleh pemahaman lebih mendalam tentang semua keterampilan proses intelektual dan ilmiah yang melekat pada tiap level inquiry sesuai pendapat dikemukakan (Nana, 2014, 2016; Nana et al., 2014; Permatasari, 2011; Rahayu et al., 2013; Samosir, 2010) menyatakan bahwa Model pembelajaran POE2WE dapat menjadikan peserta didik sebagai subjek di dalam pembelajaran. peserta didik secara aktif menemukan suatu konsep melalui pengamatan atau eksperimen secara langsung, bukan dari menghafal buku materi maupun penjelasan dari guru. Hal itu selaras dengan definisi dari Hands On Activity yakni suatu model yang dirancang untuk melibatkan siswa dalam menggali informasi dan bertanya, beraktivitas dan menemukan, mengumpulkan data dan menganalisis serta mampu membuat kesimpulan.

Pengaruh penerapan Model Pembelajaran POE2WE berbasis Hand On Activity terhadap berfikir kritis siswa sangat baik. Berfikir kritis teramati melalui interaksi siswa dalam kegiatan eksperimen dan diskusi berlangsung. Materi induksi elektromagnetik merupakan pembelajaran fisika tentang keterkaitannya dengan dunia nyata yang dijumpai dalam kehidupan siswa sehari-hari sehingga pemahamannya lebih mudah, jika dilakukan kerjasama dalam eksperimen untuk memperoleh data yang dianalisis untuk mendukung penemuan konsep-konsep induksi elektromagnetik sesuai dengan tujuan pembelajaran yang dicapai. 


\section{KESIMPULAN}

Berdasarkan hasil literatur dari berbagai sumber, bisa ditarik kesimpulan bahwa Model Pembelajaran POE2WE berbasis hands on activity dapat memberikan kemampuan berpikir kritis peserta didik pada pembelajaran fisika. Ini bisa digunakan sebagai salah satu alternatif bagi pendidik dalam usahanya meningkatkan kemampuan peserta didik untuk berpikir tingkat tinggi dan berpikir kritis terhadap pembelajaran fisika.

\section{REFERENSI}

Angga, H., Zulirfan, Sudrajad, H. (2015). Practicalities Of Alternative Electromagnetic Induction Experiment Device As A Medium Of Learning Physics In Senior High School.

Erti, P., Murni. (2017). Penerapan Model Hands On Activity untuk Meningkatkan Kemampuan Berpikir Kritis Peserta Didik pada Pembelajaran Fisika MTSN IV Koto Aur Malintang. 3 (1), 383-390.

Nana, N., \& Surahman, E. (2019). Pengembangan Inovasi Pembelajaran Digital Menggunakan Model Blended POE2WE di Era Revolusi Industri 4.0. In Prosiding SNFA (Seminar Nasional Fisika dan Aplikasinya) (Vol. 4, pp. 82-90).

Nana, S., Akhyar, M., \& Rochsantiningsih, D. (2014). The development of Predict, Observe, Explain, Elaborate, Write, and Evaluate (POE2WE) Learning Model in Physics Learning at Senior Secondary School. Development, 5(19).

Prastika, Y. Andi, Tawil, M., Amin, D. Bunga. (2013). Penerapan Pembelajaran Fisika Berbasis Hands On Activities Untuk Meningkatkan Kemampuan Berpikir Kritis Siswa Kelas X MAN 2 Model Makassar. 3 (2), 107.

Sari, W. Widya. (2016). Efektivitas Model Pembelajaran Fisika Berbasis Hands On Activity (Hoa) Terhadap Hasil Belajar Siswa Kelas X Sma Negeri 1 Rambah Samo. Skripsi.

Siswanto, Cari, Sunarno, S. (2015). Pembelajaran Fisika Menggunakan Model Team Accelerated Instruction Melalui Metode Learning Cycle Dan Hands On Activitydengan Memperiiatikan Kemampuan Berpikir Kritis Siswa Dan Interaksi Sosial. Jurnal ilmiah guru "COPE".

Uki, S. Riyan, Saehana S., Pasaribu, M. (2017). Pengaruh Model Pembelajaran Generatif Berbasis Hands-on activity pada Materi Fluida Dinamis terhadap Kemampuan Berpikir Kritis Siswa. Physics Communication. 1 (2). 